\title{
ASSESSMENT OF WATERSHED RESOURCES FOR SUSTAINABLE AGRICULTURAL DEVELOPMENT: A CASE OF DEVELOPING AN OPERATIONAL METHODOLOGY UNDER INDIAN CONDITIONS THROUGH GEOSPATIAL TECHNOLOGIES
}

\author{
K. Balasubramani* \\ School of Earth Sciences, Central University of Tamil Nadu, Thiruvarur, India - geobalas@cutn.ac.in
}

KEY WORDS: Watershed, Land and Water Resources, Potential-Utilisation Index, SDG, Geospatial Technologies

\begin{abstract}
:
The watershed based integrated approach is considered as a more efficient and appropriate approach for resource appraisal and implementation of various sustainable development measures. The present study intends to demonstrate the application of geospatial technologies in preparation of comprehensive as well as an operational framework under Indian conditions to evaluate land and water resources patterns through a case study of Andipatti watershed, located in Theni district in the State of Tamil Nadu (India). The study used widely acclaimed various empirical and quantitative models to characterise the watershed and to understand the spatial pattern of potential-utilisation levels of the watershed resources. The study used mostly remotely sensed data for understanding surface characteristics and location enabled in-situ data such as soil, rainfall and groundwater data for understanding the sub-surface characteristics of the study area. All these datasets were integrated in a GIS environment to asses soil productivity, soil erosion, surface runoff, groundwater potential, groundwater quality, crop-land suitability, groundwater suitability for agriculture, determination of potential-utilisation index and to draw land use planning strategies. Since the methodology developed in the study is mostly depends on remotely sensed data, only minimal efforts are required for any agencies to prepare a similar systematic sustainable agricultural development plan.
\end{abstract}

\section{INTRODUCTION}

\subsection{Background}

Over the last 60 years, land and water resources have been severely exploited to meet the rapidly rising demands for food and fibre through input-intensive, mechanised and intensive irrigation based agricultural practices. Currently, agriculture uses 11 per cent of the world's land surface for crop production and accounts for 70 per cent of all water withdrawn from aquifers, streams and lakes (FAO, 2016). All the agricultural lands used for cropping and livestock rearing are more susceptible to degradation than non-agricultural lands. The world's agricultural production has grown between 2.5 and 3 times in the last 60 years, at the same time the cultivated area has grown only by 12 per cent. More than 40 per cent of increase in food and fibre production achieved only by doubling the irrigated areas of the world (FAO, 2011). Now, the water shortage, soil depletion and groundwater quality deterioration are most common problems in these irrigated agricultural areas (Nachtergaele et al., 2011).

The processes of degradation are largely determined by land use change, economic investment, access to markets, availability of infrastructure and farmers' accessibility to land that allows them to produce at maximum capacity (Bai et al, 2008). Behind these obvious direct human causes, there are other deeply rooted drivers such as population pressure, poverty, poor governance and institutional framework and lack of awareness, which leads to resources degradation (Nachtergaele et al., 2011). Besides these anthropogenic impacts, biophysical factors including soil properties, climatic characteristics, topography and vegetation also sometimes interact among themselves to yield a high rate of resource degradation (Kiage, 2013).

The condition of land and water resources and their role in supporting socio-economic development is becoming more and more critical in the arid and semi-arid lands of tropical regions. These areas are highly sensitive to human interference that resulted in a severe depletion of its natural resources due to multiple interactions of natural and anthropogenic factors (AbuSharar, 2006). The vulnerability is mainly due to high population density, vagaries of the monsoon and associated floods and droughts, high rates of soil erosion, increasing groundwater exploitation, haphazard use of fertilizers, low productivity, high post-harvest yield losses, long-term climate changes, lack of environmental awareness and fragile ecosystems. Agricultural production of semi-arid lands is increases steadily but this growth has had negative side-effects on land and water resources by poorly adapted production systems which remain a serious threat to future food security (Bindraban et al., 2012).

There are various approaches being adopted to improve agricultural production systems. Despite differences, most of the approaches focus on increasing agricultural production without depleting or over-exploiting the natural resources (Verhagen et al., 2017). The main objective of sustainable agricultural development is thus to integrate people's coexistence with potentials of natural resources over the longterm so that the production from farming lands and supporting services of ecosystems are ensured (Liniger et al., 2011). However, systematic assessments for sustainable agricultural development practices in largest tropical countries like India are

* Corresponding author 
scarce (Balasubramani, 2018). With this background, the present study attempts to assess land and water resources in a watershed scale by integrating merits of global methodologies and applications of geospatial technologies towards sustainable agriculture development.

\subsection{Need for the Study}

In India, land and water resources degradation poses a considerable challenge to agricultural growth and food security. An analysis attempted by leading agencies of the nation reveals that 96.40 mha area of the country i.e. 29.3 per cent of the total geographic area of the country is undergoing a process of land degradation (ISRO, 2016). About 60 per cent of land in the country is rainfed with low productive capacity, leading to high inter-annual fluctuations in agricultural output (Mythili and Goedecke, 2016). To overcome the problems of food security and to meet out the status of self-sufficient, the country has introduced intensive farming practices in the early 1970's in the form the Green Revolution which later leads to higher rate of soil degradation, water shortage, groundwater quality deterioration and other environmental implications. Now, these problems are the foremost challenges to policymakers to balance the multiple goals of poverty eradication, food security and sustainable development. Current agricultural practices in the country are neither economically sound nor environmentally sustainable. Although India has attained self-sufficiency in food staples, the productivity of its farms is still poor mainly due to very small (less than 2 hectares) average size of land holdings and poor water resource management (Narayan, 2017). Most of the agricultural policies have primarily benefited large-scale farmers with productive land and access to water, bypassing the majority of small-scale producers, who are still in a trap of poverty, vulnerability and climatic uncertainty (FAO, 2011). In order to have sustenance of agriculture, it is necessary that the country should adopt a systematic resource assessment and management (Pathak, 2017). Many international agencies/organisations agreed that systematic action at national level is an indispensable basis for sustainable agricultural development. Hence an operational strategies needs to be developed at multiple levels within the country considering unique characteristics of the nation to address certain common issues of agriculture (Huddleston, 1990).

There is a general conscience that land and water resources should never be seen as products to be exploited, instead, they should be viewed as valuable assets and must be wisely managed (Balasubramani, 2016). Due to its complex and multifaceted nature, degradation of land and water resources cannot be easily monitored or managed. There should be a proper system in a place to assess systematically the natural resources through the principles of sustainable development. Since watersheds forms a natural as well as an ideal unit for assessing land and water resources, a basin or watershed based resources assessment would be an effective approach for holistic development of agriculture, forestry and allied activities and lessening the negative impacts of agricultural land use in India. Hence, the present study attempts to formulate a framework to assess land and water resources in a watershed scale. The study demonstrates the application of geospatial technologies for assessing land and water resources potentials as well as utilizing patterns by taking a case study area. It also attempts to outlines strategies that need to be taken by decision-makers in a bid to pursue the objectives of sustainable agricultural development for the case study area.

\subsection{Choice of Study Area}

Andipatti watershed, part of Vaigai river basin in the State of Tamil Nadu is considered as case study area. The economics of the watershed is primarily depending on agriculture and related activities and reflecting most of the major characteristics of India. The farmers of the watershed are poor and they are highly dependent on land and water resources. Most of the agricultural fields are less than one hectare but supports more than 10,000 marginal farmers. Even though the watershed falls under semiarid climate with an annual average rainfall of $790 \mathrm{~mm}$, about 40 per cent of the watershed area falls under irrigated agriculture (Balasubramani, 2018). Due to inappropriate management practices and intense crop production, the watershed faces acute problem of land and water resources degradation. Thus, Andipatti watershed is selected as case study area to demonstrate the application of geospatial technologies in the preparation of comprehensive framework to evaluate land and water resources patterns for better management strategies. However, the proposed methodological framework is applicable to all agricultural dominant rainfed watersheds of the country.

\section{METHODOLOGY}

\subsection{Physical Characteristics}

The physical characteristics of watershed were studied mainly through geospatial technologies. The survey of India (SOI) toposheets $(58 \mathrm{~F} / 12 \mathrm{SW} \& 58 \mathrm{G} / 9 \mathrm{NW})$, Geology map published by Geological Survey of India (GSI), Soil database generated by Tamil Nadu Agricultural University (TNAU) and National Bureau of Soil Survey and Land Use Planning (NBSS\&LUP), climate and groundwater data compiled by State Surface and Ground Water Board, demography data published by Census of India and village agricultural database compiled by Directorate of Economics and Statistics forms basis for preparation of base layers. All these datasets projected into common scale $(1: 25,000)$ and projection system (UTM) and stored as geodatabase using GIS software. The IRS LISS-III \& IV, CARTOSAT-1 and LANDSAT TM satellite images were used to interpret and generation of landuse / land cover, geomorphology and slope maps of the watershed. The technical details of data sources and interpretation are detailed in (Balasubramani, 2016).

\subsection{Micro-watersheds}

The watershed is further delineated into 44 micro-watersheds with the help of ArcSWAT tool. The size, shape and areal aspects of micro-watersheds were extracted from automated/semi-automated processes in ArcGIS and stored in geodatabase for detailed morphometric analysis of the watershed. The indices used for morphometric analysis and the results are detailed in (Balasubramani et al., 2019).

\subsection{Soil Productivity}

The soil productive capacity can be evaluated directly or indirectly. An assessment of soil productivity in terms of quantitative parameters is of paramount significance for proper land use planning and management. The best-known parametric system for rating the productivity of soil is the Storie Index (O'Geen et al., 2008 and Verheye, 2011). The surface and subsurface soil information including soil series, texture, permeability, depth and different chemical properties along with topographic information were used to understand the soil 
productivity of the watershed. The factors and their ratings to compute soil productivity (Storie index) are detailed in (Balasubramani, 2016).

\subsection{Soil Erosion and Surface Runoff}

Since watershed forms a natural boundary to focus on all the effects of downhill runoff, a systematic assessment of soil erosion and surface runoff within each micro-watershed would provide reliable information to draw strategies for sustainable development of agriculture. The dominant model applied worldwide to estimate the soil erosion is Revised Universal Soil Loss Equation (RUSLE) which is reasonably good in estimating soil erosion (Renard et al., 2011). The method of estimation and spatial distribution of soil erosion in the case study area are detailed in (Balasubramani et al., 2015). Similarly, NRCSCurve Number $(\mathrm{CN})$ approach provides a simple method for runoff estimation that uses empirical formulas based on rainfall, land use and soil type (Rao et al., 2010). The methodology adopted for estimating runoff of the watershed is detailed in (Bharathi, Balasubramani, 2015) and (Balasubramani, 2018).

\subsection{Groundwater Potential and Level}

Groundwater resources play a major role in the social and economic growth of the watershed. The problems of overexploitation of groundwater resources are already reported for the case study area (CGWB, 2008). Groundwater potential of the study area was assessed using resistivity, well yield and dug well data as demonstrated in (Balasubramani, 2019a). Groundwater level is also an important variable which indicate indirectly the groundwater potential zones. The seasonal groundwater levels (pre-monsoon and post-monsoon) collected from 34 open wells across the study area and long-term groundwater level data collected from the State and Central Groundwater boards were used to analyse the spatio-temporal variations in the groundwater. The methods and results of the analysis are described in (Balasubramani, 2019a).

\subsection{Land Capability and Irrigability}

Land capability and irrigability classifications are systematic approaches to evaluate the land characteristics for agricultural purposes (Sehgal, 2012). Some soils are suitable for crops, others for pastures and some others may only be suitable for forestry. Likewise some soils are suitable for extensive irrigation and some poses serious limitations. Therefore, grouping of soil units into capability and irrigability classes serve as a guide to assess the suitability of land. The factors that used to determine the capability of a soil unit in the present study are topography (slope), soil erosion, drainability, permeability, infiltration rate, surface texture, soil depth, electrical conductivity, sodicity, CEC, base saturation and organic matter content. The criteria adopted for both capability and irrigability classifications are explained in (Balasubramani, 2016).

\subsection{Crop-Land Suitability}

Land suitability evaluation plays an important role in sustainable agricultural development of a region (Davidson, 2002). The data collection, delineating land units and suitability evaluation are now largely facilitated by geospatial technologies. Keeping FAO (2007) guidelines, the thematic layers such as topography (slope), soil series (soil properties), soil erosion (RUSLE), generalised land use / land cover were intersected in GIS to prepare 787 homogenous land units. These units used to describe land qualities and characteristics as well as used to compare with the requirements of major crops. The qualities and characteristics of each land unit were compared with crop requirements and rated either as highly suitable with slight limitations (S1), moderately suitable with moderate limitations (S2), marginally suitable with severe limitations (S3) or not suitable $(\mathrm{N})$. The major crops considered for crop-land suitability analysis are paddy, maize, sorghum/bajra, ragi, pulses, cashew, groundnut, cotton, sugarcane, vegetables, coconut, mango and banana. These crops were selected based on cropping pattern, farmer's preferences and agro-ecological conditions of the study area. The details of land units, land qualities, crop selection and crop requirements are presented elaborately in (Balasubramani, 2016).

\subsection{Groundwater Suitability}

Groundwater is the main source of irrigation in the watershed. The suitability of groundwater for irrigation purpose can be examined using concentration of chloride $(\mathrm{Cl})$, magnesium ratio (MR), sodium adsorption ratio (SAR), residual sodium carbonate (RSC), soluble sodium percentage (SSP), permeability index (PI) and a method formulated by the US Salinity Laboratory (USSL). The adopted equations and spatial distribution of the quality parameters are detailed in (Balasubramani, 2019a).

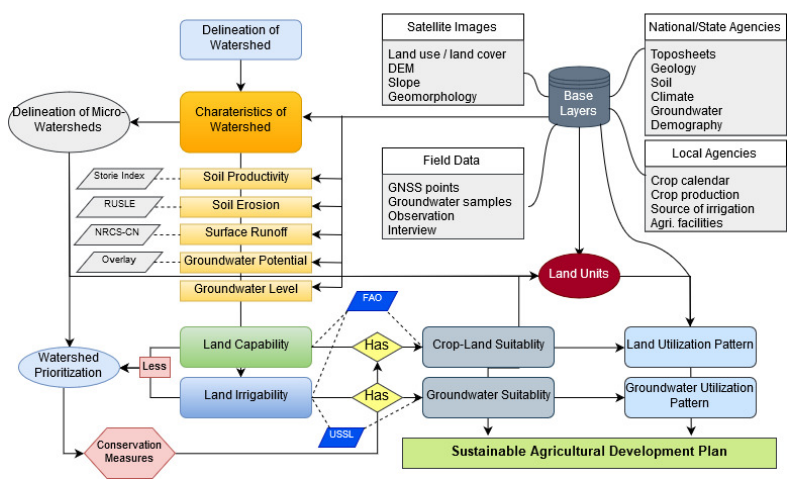

Figure 1 Workflow of developing an operational methodology for sustainable agricultural development

\subsection{Resources Utilization Pattern}

An analysis on resources potential and utilisation level in micro-level unit is essential for effective watershed management. In this study, land use / land cover pattern and soil productive capacity forms the basis for understanding the land potential-utilisation pattern. Similarly, groundwater level, groundwater quality, percentage of irrigated land, concentration of wet crops, land potential-utilisation pattern and erosion characteristics were used to determine the groundwater potential-utilisation pattern. Both the utilisation patterns were computed in a micro-watershed scale as detailed in (Balasubramani, 2016 and Balasubramani, 2019a). This kind of assessment helpful to the planners not only for understanding the utilisation level but also for regulating the present land and water utilizations scenario. 


\subsection{Watershed Prioritization}

Delineation of micro-units within the watershed and prioritization of those units are essential steps in the integrated watershed management. Each micro-watershed has unique characteristics and limitations. While suggesting soil and water conservation measures, it is important to prioritize the microwatersheds based on the characteristics and limitations in a systematic manner. With the help of geospatial technologies and multi-criteria decision-making approach, the present study prioritized micro-watersheds on the basis of morphometric parameters, soil erosion and surface runoff rates. The scheme of prioritization and method to calculate priority index are detailed in (Balasubramani, 2019).

The overall workflow of developing an operational methodology through geospatial technologies for sustainable agricultural development under Indian conditions is presented in Figure 1.

\section{RESULTS AND RECOMMENDATIONS}

The land and water resources degradation are prevalent in many forms throughout the country. It is realised widely now that the consumption of natural resources is higher than their natural regeneration capacity. This has affected the carrying capacity of the ecosystems and created an ecological imbalance, especially in the semi-arid regions. To increase productivity of agriculture in these regions, watershed based approaches are highly recommended because it found effective through a number of case studies. Further, the watershed approach is a system-based integrated approach that facilitates the holistic development of agriculture, forestry and allied activities in the watershed. By interfacing remote sensing, GIS and computation models, different management scenarios could be generated at watershed scale which would help the planners to assess the feasibility of various alternatives before selecting the one that would be most suitable. Thus, the study tries to understand various aspects of suitability of land and water resources for agricultural and other allied uses.

By comparing resource potentials and existing land use patterns, it is observed that about 22 per cent of fallow / wastelands of the watershed have excellent to good land productive capacity, but such lands are not utilised for productive purposes. Though the extreme northern watersheds found with shallow water table and good to very good groundwater quantity, the chemical properties of the watershed are not suitable for irrigation. Both quantity and quality of the groundwater are not supporting agriculture in the watersheds of central and west-central part of the study area, but the utilisation level is very high and about $2 / 3$ of the agricultural crops are water intensive. Unless and otherwise the area under intensively irrigated crops is changed to less intensively irrigated crops or dry crops, the land and water resources of the watershed cannot be saved from complete ruination.

In an area where land potential is marginal and water is a precious commodity, then structural conservation measures and optimization of land use are the most essential requirements for sustainable development. Based on land suitability, the groundwater constraints and socio-economic conditions of the watershed, sustainable land use plan is proposed for the study area (Figure 2). The conservation measures need to be taken up is discussed elaborately in (Balasubramani, 2016). If these suggested measures are adopted promptly, it would not only help to reduce resource degradation, but also reduce the severity of drought and increase the agricultural productivity of the watershed to a considerable extent. Further, the application of geospatial technologies should be encouraged in every dimensions of watershed planning because these culminations of technologies facilitate accurate resource assessments and provide sound platform for monitoring and managing the watershed resources and for achieving the sustainable development goals. The methodology of the case study can be further calibrated and could be used for optimizing utilization of land and water resources at different scales and levels.

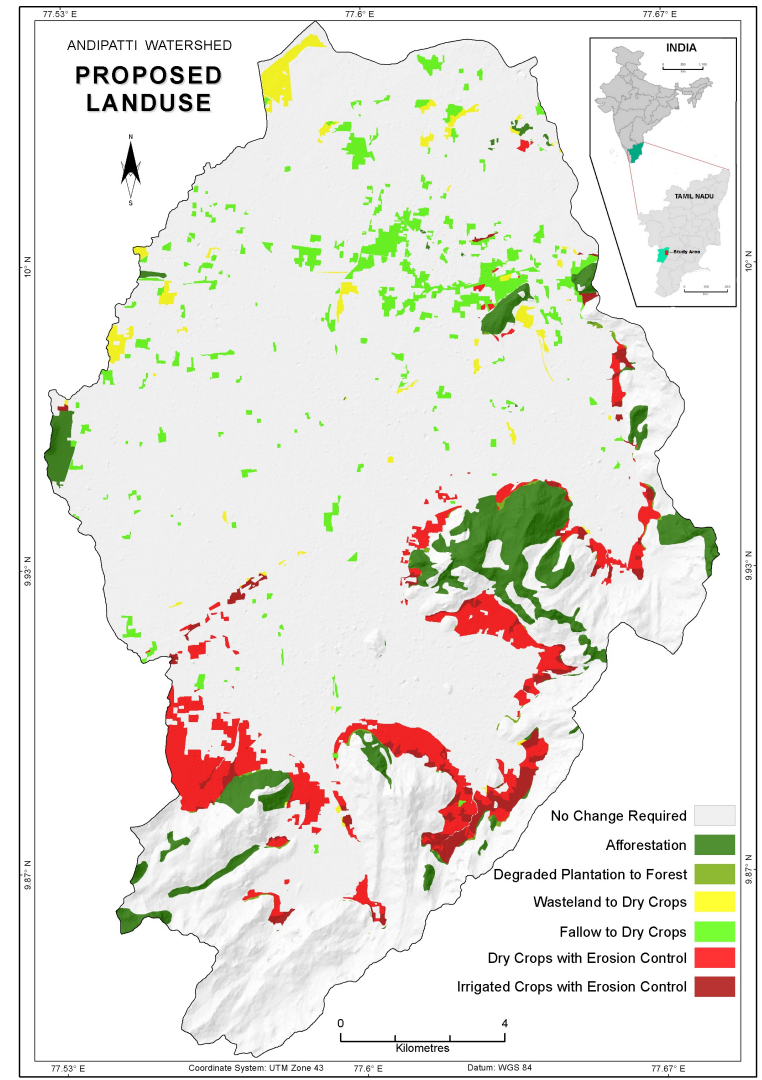

Figure 2 Proposed land use for sustainable agricultural development

\section{REFERENCES}

Abu-Sharar, T., 2006. The challenges of land and water resources degradation in Jordan: diagnosis and solutions. In: Kepner W.G., Rubio J.L., Mouat D.A., Pedrazzini F. (eds) Desertification in the Mediterranean Region. A Security Issue. NATO Security Through Science Series, 3, Springer, Dordrecht.

Bai, Z.G., Dent, D.L., Olsson, L., Schaepman, M.E., 2008. Proxy global assessment of land degradation. Soil Use Management, 24:223-234.

Balasubramani, K., Veena, M., Kumaraswamy, K., Saravanabavan, V., 2015. Estimation of soil erosion in a semiarid watershed of Tamil Nadu (India) using revised universal soil loss equation (rusle) model through GIS. Model. Earth Syst. Environ. 1:10. https://doi.org/10.1007/s40808-015-0015-4 
Balasubramani, K, 2016. Application of geospatial technologies in land and water resources evaluation for sustainable development of Andipatti watershed, Tamil Nadu, India. Ph.D. Thesis, Madurai Kamaraj University, Madurai. https://doi.org/10.13140/RG.2.2.12302.97606

Balasubramani, K., 2018. Physical resources assessment in a semi-arid watershed: An integrated methodology for sustainable land use planning. ISPRS Journal of Photogrammetry and Remote Sensing 142:358-379. https://doi.org/10.1016/j.isprsjprs.2018.03.008

Balasubramani, K., Gomathi, M., Bhaskaran, G., Kumaraswamy, K., 2019. GIS-based spatial multi-criteria approach for characterization and prioritization of microwatersheds: a case study of semi-arid watershed, South India. Appl Geomat 11:289-307. https://doi.org/10.1007/s12518-01900261-y

Balasubramani, K., Rutharvel Murthy, K., Gomathi, M., Kumaraswamy, K., 2019a. Integrated assessment of groundwater resources in a semi-arid watershed of South India: implications for irrigated agriculture. GeoJournal, 1-23 https://doi.org/10.1007/s10708-019-10050-0

Bharathi, G.P., Balasubramani, K. 2015. Rainfall - Runoff Modelling using Soil Conservation Service - Curve Number (SCS-CN) Method - A Case Study of Ungauged Andipatti Watershed, Tamil Nadu, India. In: Saravanabavan, V. (ed) Geospatial Technologies for Resources Evaluation and Management, Jayalakshmi Publications, Madurai, 59-67.

Bindraban, P.S. Marijnvan der V., LimingYe, et al., 2012. Assessing the impact of soil degradation on food production. Current Opinion in Environmental Sustainability, 4(5): 478488. https://doi.org/10.1016/j.cosust.2012.09.015

CGWB, 2008. District groundwater brochure, Theni District, Tamil Nadu. Technical report series, Central Ground Water Board, Chennai.

Davidson, D., 2002. The assessment of land resources: achievements and new challenges. Australian Geographical Studies, 40:109-128.

FAO, 2007. Land evaluation towards a revised framework. Land and water discussion paper 6. Food and Agricultural Organization, Rome.

FAO, 2011. The state of the world's land and water resources for food and agriculture - Managing systems at risk. Food and Agricultural Organization, Rome. http://www.fao.org/ docrep/017/i1688e/i1688e.pdf (15 August 2019)

FAO, 2016. Land degradation assessment in drylands - Manual for local level assessment of land degradation and sustainable land management Part-1. Food and Agricultural Organization, Rome. http://www.fao.org/ publications/card/en/c/40875549ecc8-4388-b944-26edc9b58272 (15 August 2019)

Huddleston, B., 1990. FAO's Overall Approach and Methodology for Formulating National Food Security Programmes in Developing Countries. IDS Bulletin, 21:72-80. https://doi.org/10.1111/j.1759-5436.1990.mp21003009.x

ISRO, 2016. Desertification and Land Degradation Atlas of India. Space Applications Centre, Ahmedabad.
https://vedas.sac.gov.in/vedas/downloads/atlas/DSM/Desertifica tion_Atlas_2016_SAC_ISRO.pdf

Kiage, L.M., 2013. Perspectives on the assumed causes of land degradation in the rangelands of Sub-Saharan Africa. Progress in Physical Geography: Earth and Environment, 37(5):664 684. https://doi.org/10.1177/0309133313492543

Liniger, H.P., Mekdaschi Studer, R., Hauert, C., Gurtner, M., 2011. Sustainable land management in practice - guidelines and best practices for sub-saharan Africa. Food and Agricultural Organization, Rome. http://www.fao.org/docrep/ 014/i1861e/i1861e.pdf (15 August 2019)

Mythili, G., Goedecke, J., 2016. Economics of land degradation in India. In: Nkonya, E. et al. (Eds), Economics of Land Degradation and Improvement - A Global Assessment for Sustainable Development. Springer, Heidelberg. https://doi.org/10.1007/978-3-319-19168-3 15

Nachtergaele, F. Biancalani, R., Petri, M., 2011. Land degradation. SOLAW Background Thematic Report 3, Food and Agricultural Organization, Rome. http://www.fao.org/nr/solaw/thematic-reports/en/ (15 August 2019)

Narayan, S., 2017. Indian agriculture: a long way to go. In: Pant, H. et al., (Eds) Emerging Trends in Agricultural, Environmental and Rural Developmental Challenges and Solution: An Overview, Society of Biological Sciences and Rural Development, New Jhunsi, 26-42.

O'Geen, A.T., Southard, R.J., Southard, S.B., 2008. A revised storie index for use with digital soils information. ANR Publication 8335, Agricultural and Natural Resources Communication Services, University of California. California.

Pathak, S.C., 2017. Management of natural resources for sustainable agricultural development. Emerging Trends in Agricultural. In: Pant, H. et al., (Eds) Environmental and Rural Developmental Challenges and Solution: An Overview, Society of Biological Sciences and Rural Development, New Jhunsi, 13.

Rao, K.N., Narendra, K., Latha, P.S., 2010. An integrated study of geospatial information technologies for surface runoff estimation in an agricultural watershed, India. Journal of Indian Society of Remote Sensing, 38:255-267.

Renard, K.G., Yoder, D.C., Lightle, D.T., Dabney, S.M., 2011. Universal soil loss equation and revised universal soil loss equation. In: Morgan, R.P.C. Nearing, M.A. (Eds), Handbook of Erosion Modeling, Blackwell Publishing Ltd., England, 137167.

Sehgal, J. 2012. A text book of pedology concepts and applications. Kalyani Publishers, New Delhi, 342-388.

Verhagen, J., Greet, B., Christy van, B., Simone, V., 2017. Approaches aiming at sustainable agricultural production. Wageningen Research, Report WPR-677, Wageningen http://dx.doi.org/10.18174/416937

Verheye, W., 2011. Land evaluation systems other than the FAO system. Land use, Land cover and Soil Sciences, 2:3-7.

Revised November 2019 